OPEN ACCESS

Edited by:

Silvia Platania,

University of Catania, Italy

Reviewed by:

Alfonso Landolfi,

University of Campania Luigi

Vanvitelli, Italy

Samma Faiz Rasool,

Guangzhou University, China

${ }^{*}$ Correspondence:

Zilong Cui

cui_zilong@hotmail.com

Specialty section:

This article was submitted to

Organizational Psychology,

a section of the journal

Frontiers in Psychology

Received: 24 January 2021

Accepted: 22 March 2021

Published: 03 May 2021

Citation:

Cui $Z$ and Li Y (2021) The

Relationship Between Proactive Behavior and Work-Family Conflict: A

Moderated Mediation Model.

Front. Psychol. 12:657863.

doi: 10.3389/fpsyg.2021.657863

\section{The Relationship Between Proactive Behavior and Work-Family Conflict: A Moderated Mediation Model}

\author{
Zilong Cui ${ }^{1,2 *}$ and Yuyin $\mathrm{Li}^{3}$ \\ ${ }^{1}$ Department of Human Resource Management, Yatai College of Business Administration, Jilin University of Finance and \\ Economics, Changchun, China, '2Department of Public Service Management, College of Economics and Management, \\ Dali University, Dali, China, ${ }^{3}$ Department of Public Relations, College of Economics and Management, Dali University, \\ Dali, China
}

This study aimed to explore the linking mechanisms and conditional processes underlying the relationship between proactive behavior and work-family conflict. Considering the conservation of resources theory, we argue that workplace anxiety mediates the relationship between proactive behavior and work-family conflict. Furthermore, we suggest that immediate supervisor perspective taking and employee emotional intelligence moderate this proposed indirect effect. Two-wave, multisource lagged data were collected from 450 employees of seven domestic Chinese firms to examine the hypothesized moderated mediation model. Our findings support the hypothesis that proactive behavior is positively related to work-family conflict and that workplace anxiety partially mediates this relationship. Immediate supervisor perspective taking moderates the positive association of proactive behavior with workplace anxiety and the indirect relationship between proactive behavior and work-family conflict through workplace anxiety. Emotional intelligence moderates the positive association of proactive behavior with workplace anxiety and the indirect relationship between proactive behavior and work-family conflict through workplace anxiety. The results deepen our theoretical understanding of the consequences of proactivity by demonstrating the positive associations between proactive behavior and work-family conflict. The current study also contributes to the literature by identifying workplace anxiety as a mediating mechanism explaining the relationship between proactivity and work-family conflict. Furthermore, supervisor perspective taking and employee emotional intelligence moderate the above mediating effect.

Keywords: proactive behavior, workplace anxiety, work-family conflict, perspective taking, emotional intelligence

\section{INTRODUCTION}

China has experienced rapid economic growth over the past 30 years (Rasool, 2021). China has become the global leader in manufacturing operations and the second largest economic power in the world $(\mathrm{Li}, 2018)$. The 2019 report from China's National Bureau of Statistics showed that China's manufacturing and high-tech manufacturing industries, IT services, and financial sectors grew by $6.0,8.8,18.7$, and $8.7 \%$, respectively. Chinese companies have also developed rapidly, and some of them have become world-renowned companies (e.g., Huawei, Alibaba, China Construction Bank, and China FAW Group). However, with the globalization of the economy and the rapid development of technology, the context in which organizations 
find themselves has changed dramatically. Thus, if organizations want to gain an advantage in fierce competition, it is no longer sufficient for employees to complete their tasks in line with their job descriptions. Rather, enterprises need employees to be self-starters and use their initiative to scan the workplace environment in order to identify opportunities and threats, anticipate and act on future problems, plan in anticipation of such problems, and take the initiative to implement ideas (Campbell, 2000; Crant, 2000; Fay and Frese, 2001; Griffin et al., 2007). In the organizational context, these behaviors are included within the concept of proactive behavior, whereby an employee engages in self-directed and future-oriented changes in actions in his or her work environment or work role (Griffin et al., 2007). Proactivity has received much attention in recent years because it benefits organizations in many ways, such as by increasing organizational effectiveness (Griffin et al., 2007; Grant et al., 2010) or enhancing long-term working conditions (Frese et al., 2007). Nonetheless, a small but growing body of research has revealed that there is a dark side to proactive behavior as it can have a negative impact on an individual's health, well-being, and family life (Fay and Huttges, 2017; Cangiano et al., 2019; Altura et al., 2020; Zhang et al., 2020). Work-family conflict refers to role pressure from one domain (work and family) transferring to another domain (family and work; Kahn et al., 1964; Greenhaus and Beutell, 1985). Few previous studies have addressed proactive behavior that may spill over into employees' family lives and lead to work-family conflict (Bolino and Turnley, 2005; Lin and Yu, 2019; Zito et al., 2019; Altura et al., 2020). However, the theoretical understanding of the mechanism and processes between proactive behavior and work-family conflict is far from complete. To fill this research gap, we aim to explore the mechanisms and processes underlying the effect of proactive behavior on workfamily conflict by including employees from seven enterprises (one banking enterprise, three enterprises in the high-technology industry, two enterprises in the manufacturing industry, and one trading company) in Northeast China as research participants.

Specifically, proactive behavior is regarded as a self-regulation process that involves envisioning, planning, enacting, and reflecting (Grant and Ashford, 2008). Based on the conservation of resources (COR) theory (Hobfoll, 1989) and the work-home resource (W-HR) model (ten Brummelhuis and Bakker, 2012), we theorize that proactive behavior consumes personal resources that may impede the work-family interface and cause work-family conflict. Because workplace anxiety denotes an emotional state characterized by nervousness, uneasiness, and tension associated with resource loss (Buchwald, 2010; Cheng and McCarthy, 2018; Samma et al., 2020), we suppose that proactive behavior is positively related to workplace anxiety, which in turn increases work-family conflict. Moreover, we hypothesize that immediate supervisor perspective taking and employee emotional intelligence (EI) attenuate the positive effect of proactive behavior on work-family conflict via workplace anxiety. Perspective taking has been characterized as a process in which individuals try to imagine or understand others' viewpoints (Galinsky et al., 2005). EI refers to the ability to produce, acknowledge, express, understand, and assess one's own and others' emotions and successfully cope with environmental demands and stresses (Van Rooy and Viswesvaran, 2004). Based on the COR theory (Hobfoll, 1989) and the W-HR model (ten Brummelhuis and Bakker, 2012), supervisors' perspective taking and employees' EI are contextual resources, and personal resources help individuals prevent work-family conflicts caused by resource loss. In summary, we introduce a moderated mediation model in which workplace anxiety serves as a mediator of the effect of proactive behavior on work-family conflict. Immediate supervisor perspective taking moderates the positive indirect relationship of employee proactive behavior with employee workfamily conflict through workplace anxiety such that the relationship is less positive when the employee's immediate supervisor's perspective taking is high; in addition, employee EI moderates the positive indirect relationship of proactive behavior with work-family conflict through workplace anxiety such that the relationship is less positive when employee EI is high.

This research topic is important because if proactive behavior benefits only the organization and an employee's career but harms the employee's family life, then the sustainability of this behavior is questionable. Accordingly, our study seeks to make several theoretical contributions to the literature. Firstly, our study answers the call for a more empirical investigation of the outcomes of proactive behavior in organizations by exploring the relationship between proactive behavior and work-family conflict. Secondly, although recent studies have focused on how proactive behavior influences work-family conflict, relatively little is known about the underlying mechanism of their relationship. By integrating the COR theory and the W-HR model, our research contributes to explaining the relationship between proactive behavior and work-family conflict. Thirdly, by identifying and examining supervisors' perspective taking and employees' EI as moderators of proactive behavior, this study further enriches the boundary conditions for the proactivity theory. We summarize the above analysis in the theoretical model shown in Figure 1.

The structure of the paper is as follows. In second section, we provide a Literature Review. Third section describes the Theoretical Framework and Hypotheses Development. Fourth section presents the Material and Methods, and fifth section explains the Results. Sixth section provides the Discussion, and seventh section Conclusion. Eighth section presents the Practical Implications. Finally, the final section of this paper describes the limitations of the study and future research.

\section{LITERATURE REVIEW}

\section{Proactive Behavior}

Proactive behavior is defined as an employee engaging in selfdirected and future-oriented changes in action in his or her work environment or work role (Fay and Frese, 2001; Grant and Ashford, 2008; Parker et al., 2010). This definition indicates three characteristics of proactive behavior: self-initiation, future focus, and change orientation. Grant and Ashford (2008) suggested that proactive behavior is regarded as a self-regulation process that involves envisioning, planning, enacting, and reflecting. Thus, when people are proactive at work, they 


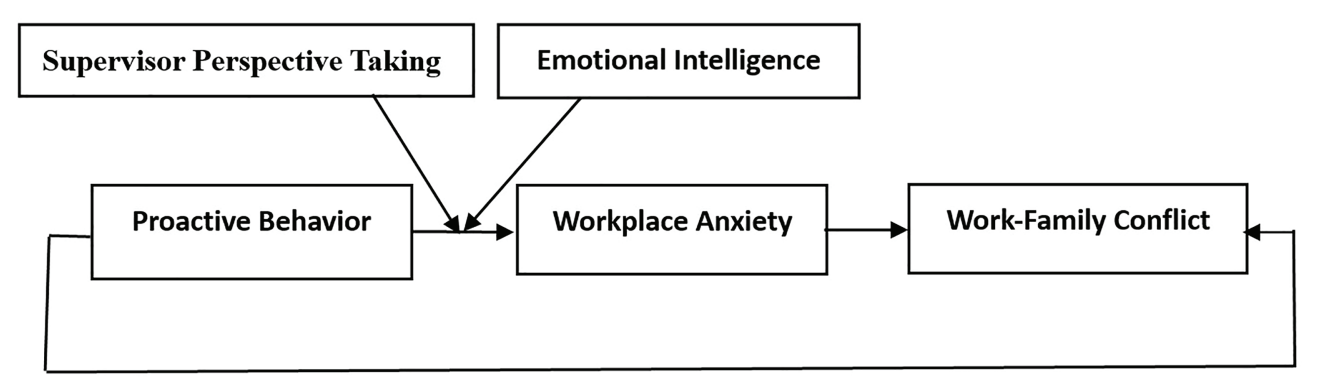

FIGURE 1 | Research model.

independently think, deliberate, plan, calculate, and act in advance (Grant and Ashford, 2008). Previous research has confirmed that individual and situational factors jointly shape individuals' proactive behavior (Bateman and Crant, 1993; Parker et al., 2006; Lebel, 2017; Wu and Parker, 2017; Binyamin and Brender-Ilan, 2018; Cai et al., 2019). Existing research has also highlighted that various forms of proactivity have positive effects on outcomes such as work performance and career success (Griffin et al., 2007; Grant et al., 2010). Compared to the antecedents of proactive behavior, the consequences of proactive behavior are not well understood (Liu et al., 2019).

\section{Work-Family Conflict}

Work-family conflict occurs when role pressure from one domain (work and family) transfers to another domain (family and work; Kahn et al., 1964; Greenhaus and Beutell, 1985). Following the perspective of Greenhaus and Beutell (1985), time-based conflict, strain-based conflict, and behavior conflict are three sources of work-family conflict. Specifically, work behavior causes work-family conflict because it is incompatible with family role expectations (Greenhaus and Beutell, 1985). For instance, a family role requires an individual to be warm, nurturing, and empathetic. Such expectations are in contrast to job role expectations, including requirements to be objective, neutral, and calm.

\section{Workplace Anxiety}

Workplace anxiety refers to an emotional state reflecting nervousness, uneasiness, and tension in the workplace (Cheng and McCarthy, 2018). When individuals are upset by things such as meeting timelines, uncertainty regarding things that may or may not happen, and social conflict, they may more easily experience anxiety (Miceli and Castelfranchi, 2005; MacLeod and Mathews, 2012; Grupe and Nitschke, 2013; Cheng and McCarthy, 2018; Rasool et al., 2020). Previous literature has suggested that workplace anxiety is positively associated with unethical workplace behavior, risk-taking behavior, and organizational turnover (Rodell and Judge, 2009; Kouchaki and Desai, 2015; Mannor et al., 2016).

\section{Perspective Taking}

Perspective taking has been conceptualized as a process in which an observer attempts to infer the thoughts, motives, and/or feelings of others (Galinsky et al., 2005; Parker et al., 2008).
Perspective taking is often considered to be an active cognitive process - perspective takers mentally simulate what it would be like to be someone else and to see the world from that person's perspective. Perspective taking has many positive benefits for organizations because it can increase psychological closeness, coordination, cooperation, proactive service performance, and helping (Falk and Johnson, 1977; Galinsky et al., 2005; Shih et al., 2009; Ku et al., 2015; Huo et al., 2019).

\section{Emotional Intelligence}

EI has been defined as the disposition or ability allowing one to develop, identify, express, understand, and appraise one's own and other people's emotions to successfully cope with environmental demands and pressures (Van Rooy and Viswesvaran, 2004). George (2000) and Mayer et al. (1999) suggested that EI involves four aspects: (a) the perception of emotions, (b) the integration and assimilation of emotions, (c) the understanding of emotions, and (d) emotion regulation. The perception of emotions refers to individuals' ability to accurately identify emotions in themselves and in others. The integration and assimilation of emotions allow people to use emotions to guide their thinking and facilitate decision making. The understanding of emotions concerns how people understand their emotions. The fourth dimension, emotion regulation, refers to the extent to which individuals can manage their own and others' emotions. EI has been regarded as a predictor of various domains, such as job performance, leadership, emotional labor, trust, work-family conflict, stress, mental health, and well-being (Jordan et al., 2002; Fulmer and Barry, 2004; Daus and Ashkanasy, 2005; Humphrey et al., 2008; Sánchez-Álvarez et al., 2016).

\section{THEORETICAL FRAMEWORK AND HYPOTHESIS DEVELOPMENT}

\section{Proactive Behavior and Work-Family Conflict}

According to Bindl et al. (2012), proactive behavior is a selfregulation progress that involves envisioning, planning, enacting, and reflecting. Thus, proactivity requires thinking independently, carefully deliberating, planning, and calculating, and acting in 
advance (Grant and Ashford, 2008). Regarding role theory, when people devote more time and energy to their work roles, they tend to have less time and energy to spend with family members and fulfill their family duties (Arlie, 1997). Thus, proactive employees are more inclined to prioritize work demands and focus less attention on family demands and obligations (Altura et al., 2020). Consequently, proactive employees are likely to experience conflict between work and family because they do not sufficiently fulfill family obligations. Indeed, previous studies have suggested a positive relationship between proactive behavior and work-family conflict. For example, Altura et al. (2020) reported that proactive individuals are more inclined to prioritize their work needs, resulting in greater work to family interference. Bolino and Turnley (2005) suggested that higher levels of individual initiative are associated with higher levels of work-family conflict. Zito et al. (2019) argued that job crafting, which is considered a specific proactive behavior, is positively correlated with work-family conflict. Taken together, the above arguments and evidence suggest the following:

Hypothesis 1: Proactive behavior is positively related to work-family conflict.

\section{Proactive Behavior and Workplace Anxiety}

Proactivity may require an employee to focus on the future, challenge the status quo, and "mak[e] things happen" (Parker et al., 2019). Although proactive behavior may promote career success and performance for employees (Fuller and Marler, 2009; Thomas et al., 2010; Tornau and Frese, 2015), scholars have argued that proactive behavior is not always appreciated by leaders and coworkers and may lead to some negative outcomes (Spychala and Sonnentag, 2011; Fay and Huttges, 2017; Pingel et al., 2019; Cangiano et al., 2020; Zhang et al., 2020). In this paper, we argue that proactivity generates workplace anxiety. The reasons are as follows. Firstly, proactive work behavior involves a future focus. Being proactive often results in changes to established work processes, and the result of being proactive is always unknown (Bolino et al., 2010). This may lead proactive individuals to experience uncertainty and unpredictability at work. Secondly, the changing nature of proactive behavior may result in changes to work roles, organizational norms, and work procedures (Fay and Frese, 2001; Grant and Ashford, 2008). In an interdependent work environment, violating or changing the prescribed pattern means that proactivity will affect other people's work. Thus, being proactive is not always welcome or may even be rejected or envied by others (Bolino et al., 2010; Sun et al., 2020; Zhang et al., 2020). For example, previous studies have suggested that, although proactive behavior is necessary, it should conform to the leader's expectations (Campbell, 2000; Grant et al., 2010). For this reason, engaging in proactive behavior is considered "risky" because it generates social friction among proactive employees. Fay and Huttges (2017) proposed that these aversive experiences of social friction and social tension negatively affect individuals. Furthermore, when people are proactive at work, they carefully deliberate, plan, calculate, and act in advance (Grant and Ashford, 2008). Their proactive behavior consumes resources in terms of time and energy (Strauss et al., 2017; Pingel et al., 2019; Urbach and Weigelt, 2019). Because time and energy are limited resources, proactive employees also often experience time conflict and fatigue at work (Fay and Frese, 2001; Cangiano et al., 2020). Therefore, we can expect that the uncertainty, time conflict, and social friction caused by proactive behavior will lead proactive employees to experience workplace anxiety. Based on this rationale, we hypothesize the following:

Hypothesis 2: Proactive behavior is positively related to workplace anxiety.

\section{Workplace Anxiety and Work-Family Conflict}

We expect that a positive relationship exists between workplace anxiety and work-family conflict. Anxiety is a symptom of strain that makes individuals feel nervous, uneasy, and tense (McCarthy et al., 2016). It has been suggested that symptoms of strain, such as tension, anxiety, and fatigue in one's role (work or family), can affect one's performance in another role (family or work; Sell and Schuler, 1981; Michel et al., 2011). Thus, the negative affect of an anxious employee is more likely to spill over into the family domain and interfere with the performance of family duties. Previous literature has shown that anxious employees are more inclined than employees who are not anxious to interact with their partners with less warmth and supportiveness (Salovey and Rosenhan, 1989; Matthews et al., 1996) and express more criticism and dissent (Story and Repetti, 2006) when they return home from work. Furthermore, anxious employees experience cognitive interference, which refers to the tendency to spend considerable time ruminating on task-irrelevant or off-task thoughts (Sarason et al., 1996). For example, when employees feel anxious about a work task or worry about expected failure, these feelings will occupy their minds and cause them to spend a large amount of time cognitively processing and thinking about these tasks (MacIntyre and Gardner, 1994; Cheng and McCarthy, 2018). Therefore, interference with mental processes due to workplace anxiety can be expected to inevitably reduce performance in the family domain. Michel et al. (2011) performed a meta-analysis that showed that negative affective personal traits characterized by stress, anxiety, and dissatisfaction had a significant positive effect on work-family conflict. According to the COR theory (Hobfoll, 1989), workplace anxiety triggers an emotion-focused coping strategy that causes a resource drain, which manifests in the depletion of emotion regulation. Emotional exhaustion, in turn, increases work-family conflict (Grandey, 2003; Goldberg and Grandey, 2007; Trougakos et al., 2020). Based on the proposition above, we hypothesize the following:

Hypothesis 3: Workplace anxiety is positively related to work-family conflict. 


\section{The Mediating Role of Workplace Anxiety}

We expect proactive behavior to have indirect effects on workfamily conflict through workplace anxiety. That is, individuals who engage in proactive behavior at work experience workplace anxiety, which leads to work-family conflict. Considering the basic assumptions of the COR theory (Hobfoll, 1989) and the W-HR model (ten Brummelhuis and Bakker, 2012), initial resource losses will lead to future resource losses. As such, work resource loss primarily leads to stress and strain and further results in poorer outcomes at home (Halbesleben et al., 2014). Thus, proactive behavior at work requires high levels of personal resource consumption (e.g., time, energy, and self-effort), and the depletion of personal resources caused by proactivity leads to job strain and anxiety (Bolino et al., 2010; Hahn et al., 2012; Cangiano et al., 2019; Pingel et al., 2019). In turn, workplace anxiety is more likely to spill over to the home domain and cause work-family conflict (Doby and Caplan, 1995). Based on the proposition above, we hypothesize the following:

Hypothesis 4: Workplace anxiety mediates the relationship between proactive behavior and workfamily conflict.

\section{The Moderating Role of Perspective Taking}

Leaders' perspective taking can be transformational if they are able to assume the perspective of a follower (Parker et al., 2008; Gregory et al., 2011). We expect an immediate supervisor's perspective taking to moderate the relationship between employee proactive behavior and workplace anxiety. Firstly, perspective taking serves to increase openness to diverse perspectives, increases the desire to help, builds trust, and facilitates knowledgesharing behavior (De Dreu et al., 2000; Galinsky and Moskowitz, 2000; Moates et al., 2007; Flinchbaugh et al., 2016). Proactive employees whose leaders score high in perspective taking may be more likely to obtain help from their leaders. With help from their leaders, employees can successfully implement proactive behavior with less time, energy, and effort, which ultimately relieves their workplace anxiety. Furthermore, leaders' perspective taking helps to build trust with subordinates. When proactive employees feel trusted, risky proactive behavior is perceived as safe, with reduced uncertainty and social tension. According to the self-determination theory (Ryan and Deci, 2008), trusted employees who feel competent tend to report feeling greater vigor and less anxiety (Spreitzer, 1995; Thatcher et al., 2007). Thus, when an immediate supervisor is strong in perspective-taking ability, proactive employees are more likely to be motivated (Galinsky and Schweitzer, 2016). Conversely, when an immediate supervisor is weak in perspective-taking ability or is even punitive, proactive employees report experiencing more workplace anxiety (Cangiano et al., 2019).

Moreover, we argue that the positive effect of proactivity on work-family conflict through workplace anxiety may be weaker for employees who experience high levels of perspective taking from their supervisors. Specifically, we expect immediate supervisor perspective taking to moderate the indirect effects of employee proactivity on employee work-family conflict. Evidence suggests that leaders' openness to proactivity can facilitate the positive effect of proactivity (Huo et al., 2013; Parker et al., 2019). Integrating the COR theory (Hobfoll, 1989) and the W-HR model (ten Brummelhuis and Bakker, 2012), we expect that leaders' perspective taking, which represents their support, facilitates employees' personal resource transitions from the work domain to the home domain. Thus, proactive employees whose leaders score high in perspective taking tend to experience lower anxiety and less work-family conflict. In contrast, when the supervisor exhibits low levels of perspective taking, proactivity among employees is more likely to trigger workplace anxiety and further cause work-family conflict. In summary, we hypothesize the following:

Hypothesis 5: Immediate supervisor perspective taking moderates the positive relationship between proactive behavior and workplace anxiety so that the relationship is weaker for immediate supervisor with high levels of perspective taking (in contrast to immediate supervisor with low levels of perspective taking).

Hypothesis 6: Immediate supervisor perspective taking moderates the positive impact of proactive behavior on work-family conflict via workplace anxiety so that the relationship is weaker for immediate supervisor with high levels of perspective taking (in contrast to immediate supervisor with low levels of perspective taking).

\section{The Moderating Role of Emotional Intelligence}

We expect EI to moderate the relationship between proactive behavior and workplace anxiety such that the relationship is less positive when EI is high than when EI is low. People with higher EI have the ability to better perceive, understand, and manage their emotions. Therefore, people with high EI typically have a more positive mood and are able to cope with negative emotional states associated with mood and anxiety (Schutte et al., 2002; Foster et al., 2018; MartínezMonteagudo et al., 2019). In previous studies, EI has been found to be negatively related to social interaction anxiety, writing anxiety, communicative anxiety, and foreign language anxiety (Summerfeldt et al., 2006; Dewaele et al., 2008; Huerta et al., 2017). Therefore, although proactive behavior triggers workplace anxiety, EI helps employees alleviate this negative emotional state. Prior studies have found that, because people with EI are able to regulate their moods, EI buffers the negative effects of stress (Görgens-Ekermans and Brand, 2012; Fu et al., 2020). Moreover, people with EI can perceive and manage others' emotions. Thus, people with high EI take into account the feelings of others at work. Hence, high EI can help people reduce workplace anxiety caused by interpersonal tension from their proactive behavior. In a similar vein, Grant (2013) proposed that 
knowledge of emotion regulation enables employee voice to elicit favorable performance evaluations and, thus, reduces the threatening interpersonal aspects of employee voice. Hence, EI reduces the positive associations between proactive behavior and workplace anxiety. In contrast, for proactive employees who have low levels of EI or relational knowledge, their proactivity is not accepted or appreciated, thus increasing their workplace anxiety.

Moreover, we argue that the positive effect of proactivity on work-family conflict through workplace anxiety may be weaker for employees with high EI. Specifically, we expect employee EI to weaken the indirect effects of proactivity on work-family conflict. Individuals with high EI are skilled at emotional expression, emotion identification, and emotion management. Therefore, they can handle negative affect and stress that may spill over from work to family (Edwards, 2006). Similarly, individuals with high EI are likely more adaptable in high-pressure conditions and are likely to see pressure as a challenge instead of as a threat (Schneider et al., 2013). Thus, good use of emotional skills might help people with high EI to have strong well-being and health (Zeidner et al., 2012; Sánchez-Álvarez et al., 2016). Based on the COR theory (Hobfoll, 1989) and the W-HR model (ten Brummelhuis and Bakker, 2012), EI is considered a key resource that might be useful in protecting against resource loss and aid in recovery from losses (Halbesleben et al., 2014). Therefore, employees with high EI may be better at coping with strain and anxiety prompted by proactivity, which may in turn reduce their work-family conflict caused by the resource loss. In contrast, proactive employees with low EI are unable to cope with the stress and anxiety caused by proactive behavior, which ultimately negatively affects their family lives. In summary, we hypothesize the following:

Hypothesis 7: EI moderates the positive relationship between proactive behavior and workplace anxiety so that the relationship is weaker for employees with high levels of EI (in contrast to employees with low levels of EI).

Hypothesis 8: EI moderates the positive impact of proactive behavior on work-family conflict via workplace anxiety so that the relationship is weaker for employees with high levels of EI (in contrast to employees with low levels of EI).

\section{MATERIALS AND METHODS}

\section{Instrument Development}

In this study, a questionnaire was used for data collection (Rasool et al., 2019; Zhou et al., 2020). The questionnaire comprised 36 items (three items for proactive behavior, eight items for workplace anxiety, five items for work-family conflict, four items for immediate supervisor perspective taking, and 16 items for EI) scored with a five-point Likert scale ( $1=$ strongly disagree and
$5=$ strongly agree). The Brislin (1980) back-translation procedure was employed for all measures, which were provided to participants in Chinese. To enhance the rigor of the study, a pilot study was conducted to check the instrument's reliability and validity. An initial questionnaire was distributed to 32 professionals (12 professors, $13 \mathrm{PhD}$ students, and seven human resource management specialists). These professionals recommended changes to the research instrument.

\section{Data Collection}

To minimize common method bias, we used a two-wave, multisource (supervisor-subordinate dyads) design to collect data (Podsakoff et al., 2003). The data were collected for approximately 1 month from September to October 2020. We recruited seven human resource (HR) managers from banks, manufacturing companies, high-technology companies, and trading companies (one banking enterprise, three enterprises in the high-technology industry, two enterprises in the manufacturing industry, and one trading company) who attended a part-time MBA program in three cities (Changchun, Dalian, and Harbin) in Northeast China. After speaking with these HR managers about the survey procedure and content, we directed them to randomly recruit full-time employees in their organizations.

When the survey was conducted, we first communicated with the HR management department of each company, and the HR departments communicated and coordinated with all relevant departments and explained the purpose of our questionnaire survey. Each HR department was asked to provide the names and job numbers of volunteer supervisor-subordinate dyads. Survey questionnaires were matched by codes determined by the researchers. Two graduate psychology students who were independent from the organizations were assigned to conduct the surveys. The participants finished the questionnaire in their own time and returned it in a sealed envelope to the research assistant. The survey instructions informed the participants of the objectives of the study, and the confidential nature of the participants' responses was strictly ensured. The participants were asked to record their identification numbers so that the individual responses could be matched over time. At time 1 (on a Friday afternoon), 130 supervisors of employees were invited to report their perspective taking and subordinate proactive behavior over the past week; 122 supervisors completed the survey (response rate of 93.84\%). A total of 580 employees were invited to report their demographic information (gender, age, marital status, education, and tenure), EI, and workplace anxiety over the past week, and 494 completed the survey (response rate of $85.17 \%$ ). After screening out unmatched records, 490 subordinates and 120 supervisors remained. At time 2 (the end of the weekend), we asked the subordinates to report the work-family conflict they experienced over the past weekend. The subordinates were asked to answer the questions between 1900 and 2,100 h. The researcher sent a message via WeChat to remind the subordinates to complete the questionnaire on time and asked them to take a picture of the questionnaire to give feedback. At time 2, 470 participants 
completed the survey. After excluding missing data and non-matched data, we ultimately obtained 450 valid questionnaires. To improve the quality of the questionnaire data, we provided compensation of approximately US $\$ 8$ to the supervisors and US $\$ 5$ to the subordinates.

\section{Measures \\ Proactive Behavior}

The proactive behavior items were adopted from Griffin et al. (2007). The three items were rated on a five-point Likert scale (ranging from 1 = strongly disagree to $5=$ strongly agree). A sample item is "I initiated better ways of performing my core tasks" (Cronbach's $\alpha=0.75$; see Table 1 ).

\section{Workplace Anxiety}

The workplace anxiety items were adopted from McCarthy et al. (2016). The eight items were rated on a five-point Likert scale (ranging from 1 = strongly disagree to $5=$ strongly agree). A sample item is "Even when I try as hard as I can, I still worry about whether my job performance will be good enough" (Cronbach's $\alpha=0.88$; see Table 1 ).

\section{Work-Family Conflict}

The work-family conflict items were adopted from Netemeyer et al. (1996). The five items were rated on a five-point Likert scale (ranging from 1 = strongly disagree to $5=$ strongly agree). A sample item is "The demands of my work interfere with my home and family life" (Cronbach's $\alpha=0.83$; see Table 1).

\section{Immediate Supervisor Perspective Taking}

The items on immediate supervisor perspective taking were adopted from Grant and Berry (2011). The four items were rated on a five-point Likert scale (ranging from 1 = strongly disagree to 5 = strongly agree). A sample item is "On the job, my supervisor will try to take my perspective" (Cronbach's $\alpha=0.89$; see Table 1 ).

\section{Emotional Intelligence}

The EI items were adopted from Wong and Law (2002). The 16 items were rated on a five-point Likert scale (ranging from 1 = strongly disagree to $5=$ strongly agree). Sample items include the following: "I always know my friends' emotions from their behavior" (others' emotion appraisals), "I have a good understanding of my own emotions" (self-emotion appraisal), "I always set goals for myself and then try my best to achieve them" (use of emotion), and "I am able to control my temper and handle difficulties rationally" (regulation of emotion; Cronbach's $\alpha=0.95$; see Table 1).

\section{Control Variables}

Gender, age, marital status, education, and tenure have been identified as potential predictors of work-family conflict in previous studies (Bolino and Turnley, 2005; Byron, 2005; Gao et al., 2013). Following prior suggestions to use control variables (Carlson and Wu, 2012; Bernerth and Aguinis, 2016), we controlled for employees' gender, age, marital status, education, and tenure to better estimate the effects of proactive behavior on work-family conflict.

\section{Demographic Information and Participant Summary}

A total of 450 employees were randomly selected from seven enterprises from three cities (Changchun, Dalian, and Harbin) in Northeast China. Of the sample, $52.4 \%$ of the participants were male. Regarding their marital status, $55.3 \%$ were married. The age distribution of the sample was as follows: $18-20$ years (0.9\%), 21-25 years (28.7\%), 26-30 years (35.1\%), 31-35 years (19.1\%), 36-40 years $(10.2 \%)$, and 41 years or over $(6 \%)$. A total of $48.9 \%$ of the participants had a bachelor's degree, and approximately $48.7 \%$ had 1-5 years of work experience.

\section{RESULTS}

\section{Data Analysis Strategy}

Firstly, statistical analyses were carried out with SPSS 24.0 to determine the reliability of the data and to calculate the descriptive statistics and correlations among the variables. Secondly, the measurement model was tested using confirmatory factor analysis (CFA) with AMOS 17.0 to assess the variables' discriminant validity. Thirdly, the moderated mediation model was tested using PROCESS, as recommended by Muller et al. (2005). The mediating effect was assessed using 5,000 bootstrap estimates based on $95 \%$ bias-corrected confidence intervals (CIs; PROCESS, model 4; Hayes, 2013). The moderation model was tested using the PROCESS macro (model 7; Edwards and Lambert, 2007; Hayes, 2013). The CIs were calculated, and if they did not include zero, the null hypothesis was rejected in support of the study hypothesis.

\section{Descriptive Statistical Analysis}

The means, SD, and correlations of the study variables are shown in Table 1. As expected, proactive behavior (time 1) was positively and significantly related to workplace anxiety (time $1 ; r=0.58, p<0.01$ ) and work-family conflict (time $2 ; r=0.49, p<0.01$ ). Additionally, workplace anxiety (time 1) was positively related to work-family conflict (time $2 ; r=0.57$, $p<0.01$ ). Workplace anxiety (time 1 ) was also positively related to EI (time $1 ; r=-0.11, p<0.05$ ).

\section{Measurement Model}

A CFA of the above five measures was conducted to analyze discriminant validity using AMOS 17.0 with maximum likelihood estimation procedures. As shown in Table 2, we found good support for the five-factor solution (proactive behavior, workplace anxiety, work-family conflict, immediate supervisor perspective taking, and EI), which showed an adequate fit to the data: $\chi^{2}=1,493.81$, degrees of freedom $(d f)=568$, comparative fit index $(\mathrm{CFI})=0.92$, incremental fit index $(\mathrm{IFI})=0.92$, 
TABLE 1 | Results of the descriptive statistical analysis.

\begin{tabular}{|c|c|c|c|c|c|c|c|c|c|c|c|c|}
\hline Variables & $\mathbf{M}$ & SD & 1 & 2 & 3 & 4 & 5 & 6 & 7 & 8 & 9 & 10 \\
\hline 1. Gender ${ }^{\mathrm{a}}$ & 0.48 & 0.50 & & & & & & & & & & \\
\hline 2. $\operatorname{Age}^{\mathrm{b}}$ & 3.27 & 1.18 & 0.00 & & & & & & & & & \\
\hline 3. Marital status ${ }^{c}$ & 0.55 & 0.49 & -0.05 & $0.12^{* * *}$ & & & & & & & & \\
\hline 4. Education ${ }^{d}$ & 2.64 & 0.87 & $-0.09^{*}$ & 0.00 & $0.13^{* *}$ & & & & & & & \\
\hline 5. Tenure $^{e}$ & 2.79 & 1.42 & -0.03 & $0.37^{* *}$ & $0.18^{* *}$ & 0.08 & & & & & & \\
\hline 6. Proactive behavior (time 1) & 3.71 & 0.67 & $-0.11^{*}$ & 0.05 & 0.01 & 0.06 & -0.09 & $(0.75)$ & & & & \\
\hline 7. Workplace anxiety (time 1) & 3.59 & 0.54 & $-0.12^{* *}$ & 0.01 & 0.07 & 0.03 & -0.02 & $0.58^{* *}$ & $(0.88)$ & & & \\
\hline 8. Work-family conflict (time 2) & 3.86 & 0.52 & $-0.10^{*}$ & $0.09^{*}$ & $0.10^{*}$ & 0.08 & 0.03 & $0.49^{* *}$ & $0.57^{* * *}$ & $(0.83)$ & & \\
\hline 9. Emotional intelligence (time 1) & 3.39 & 0.95 & -0.01 & -0.02 & -0.07 & $0.15^{* *}$ & $0.22^{* *}$ & -0.03 & $-0.11^{*}$ & -0.05 & $(0.95)$ & \\
\hline $\begin{array}{l}\text { 10. Immediate supervisor } \\
\text { perspective taking (time } 1 \text { ) }\end{array}$ & 3.23 & 1.36 & -0.00 & -0.07 & -0.04 & -0.07 & -0.04 & 0.06 & 0.03 & 0.03 & -0.03 & $(0.89)$ \\
\hline
\end{tabular}

$n=450$; Cronbach's alpha reliability coefficients are displayed on the diagonal. ${ }^{*} p<0.05 ;{ }^{* *} p<0.01$

a Male $=0$; Female $=1$.

${ }^{b}$ Under $20=1 ; 20-25=2 ; 36-30=3 ; 31-35=4 ; 36-40=5 ; 41$ and over $=6$.

Single $=0$; Married $=1$.

${ }^{\circ}$ High school = 1; College degree $=2$; Bachelor's degree $=3$; Master's degree and over $=4$.

eUnder 1 year $=1 ; 1-3$ years $=2 ; 3-5$ years $=3 ; 5-7$ years $=4 ; 7$ years and over $=5$.

TABLE 2 | Confirmatory factor analysis.

\begin{tabular}{|c|c|c|c|c|c|c|}
\hline Measurement models & $\chi^{2}$ & $d f$ & CFI & TLI & IFI & RMSEA \\
\hline Five-factor model & $1,493.81$ & 568 & 0.92 & 0.91 & 0.92 & 0.060 \\
\hline $\begin{array}{l}\text { Four-factor model (combining proactive behavior and workplace anxiety into one } \\
\text { factor) }\end{array}$ & $1,762.03$ & 575 & 0.90 & 0.89 & 0.90 & 0.068 \\
\hline $\begin{array}{l}\text { Three-factor model (combining proactive behavior, perspective taking, and El into } \\
\text { one factor) }\end{array}$ & $2,861.31$ & 578 & 0.82 & 0.81 & 0.83 & 0.090 \\
\hline $\begin{array}{l}\text { Two-factor model (combining proactive behavior, perspective taking, work-family } \\
\text { conflict, and El into one factor) }\end{array}$ & $4,882.19$ & 579 & 0.63 & 0.60 & 0.63 & 0.132 \\
\hline
\end{tabular}

CFI, comparative fit index; IFI, incremental fit index; TLI, Tucker-Lewis index; RMSEA, root mean square error of approximation.

Tucker-Lewis index $(\mathrm{TLI})=0.91$, and root mean square error of approximation (RMSEA) $=0.060$.

\section{Hypothesis Testing}

We used SPSS 24.0 to test our hypotheses. We followed the procedures recommended by Muller et al. (2005) and used multiple regression analysis to test our moderated mediation model. We centered proactive behavior, workplace anxiety, EI, and immediate supervisor perspective taking to reduce multicollinearity according to Aiken and West (1991).

Firstly, we tested the indirect effects. As shown in Table 3, the results from the regression analysis of the mediation model indicated that proactive behavior was positively and significantly associated with work-family conflict (model $7 ; \beta=0.48$, $p<0.001)$ and workplace anxiety (model $1 ; \beta=0.58, p<0.001$ ). Workplace anxiety was positively associated with work-family conflict (model $8 ; \beta=0.42, p<0.001$ ). Thus, Hypothesis 1 , 2 , and 3 were supported. To test the mediating effect, we assessed the mediation model using 5,000 bootstrap estimates based on 95\% bias-corrected CIs (PROCESS, model 4; Hayes, 2013). The bootstrapping results showed that the indirect effect of proactive behavior on work-family conflict (indirect effect $=0.37$, $\mathrm{SE}=0.46,95 \% \mathrm{CI}=0.29-0.47)$ was significant. Thus, Hypothesis 4 was supported.
Secondly, we tested the moderation model using the PROCESS macro (model 7; Edwards and Lambert, 2007; Hayes, 2013). In Hypothesis 5, we proposed the moderating role of immediate supervisor perspective taking in the positive relationship between proactive behavior and workplace anxiety. As shown in model 3 in Table 3, the interaction term of proactive behavior and immediate supervisor perspective taking was statistically significant $(\beta=-0.56, p<0.01)$. Furthermore, a simple slope test revealed that the effect of proactive behavior on workplace anxiety was stronger for low levels of immediate supervisor perspective taking $(\beta=0.54, \mathrm{SE}=0.03, p<0.001)$ than for high levels $(\beta=0.39, \mathrm{SE}=0.04, p<0.001$; see Figure 2). Thus, Hypothesis 5 was supported. Moreover, we used the approach of Preacher et al. (2007) to test the conditional indirect effect. As indicated in Table 4, proactive behavior had a stronger positive and statistically significant conditional indirect effect on work-family conflict via workplace anxiety when the immediate supervisor had low levels of perspective taking $(-1 \mathrm{SD}$, indirect effect $=0.22, \mathrm{SE}=0.35,95 \% \mathrm{CI}=0.16-0.30)$ than when the immediate supervisor had high levels of perspective taking $(+1 \mathrm{SD}$, indirect effect $=0.16, \mathrm{SE}=0.28,95 \% \mathrm{CI}=0.11-0.22)$. Furthermore, the difference in the indirect effect was significant $(\Delta \beta=-0.06, \mathrm{SE}=0.028,95 \% \mathrm{CI}=-0.12$ to -0.00$)$. Thus, Hypothesis 6 was supported. 


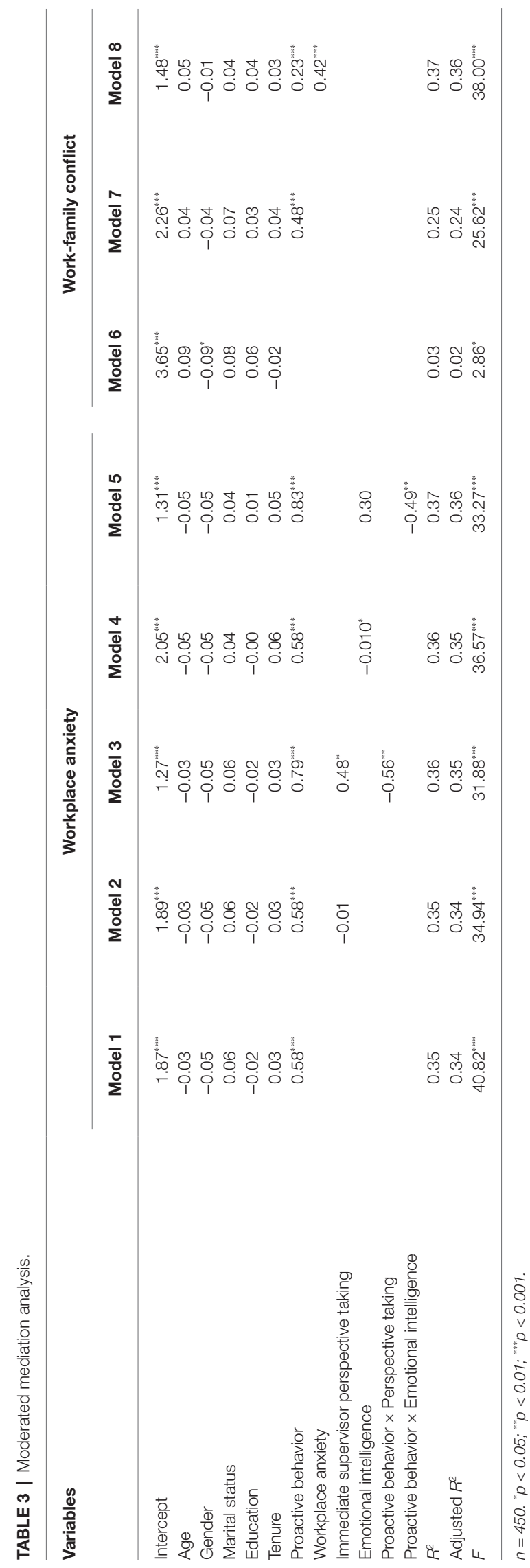

Thirdly, we also tested Hypothesis 7 and 8 using the PROCESS macro (model 7; Edwards and Lambert, 2007; Hayes, 2013). In Hypothesis 7, we proposed the moderating role of EI in the positive relationship between proactive behavior and workplace anxiety. As shown in model 5 in Table 3, the interaction term of proactive behavior and EI was statistically significant $(\beta=-0.49, p<0.01)$. Furthermore, a simple slope test revealed that the effect of proactivity on workplace anxiety was stronger for low EI $(\beta=0.51, \mathrm{SE}=0.03, p<0.001)$ than for high EI $(\beta=0.39, \mathrm{SE}=0.04, p<0.001$; see Figure 3$)$. Thus, Hypothesis 7 was supported.

Additionally, as indicated in Table 5, proactivity had a stronger positive and statistically significant conditional indirect effect on work-family conflict via EI when EI was low (-1 $\mathrm{SD}$, indirect effect $=0.21, \mathrm{SE}=0.33,95 \% \mathrm{CI}=0.15-0.28$ ) than when $\mathrm{EI}$ was high $(+1 \mathrm{SD}$, indirect effect $=0.16, \mathrm{SE}=0.27$, $95 \% \mathrm{CI}=0.11-0.22$ ). Furthermore, the difference in the indirect effect was significant $(\Delta \beta=-0.05, \mathrm{SE}=0.027,95 \% \mathrm{CI}=-0.10$ to -0.00$)$. Thus, Hypothesis 8 was supported.

\section{DISCUSSION}

Drawing upon the COR theory (Hobfoll, 1989) and the W-HR model (ten Brummelhuis and Bakker, 2012), we developed and tested a moderated mediation model explaining how and when proactive behavior affects work-family conflict. In this study, we identified a positive theoretical link between proactive behavior and work-family conflict that strengthens the understanding of the outcomes of proactivity. Our empirical results support the proposition that proactivity is positively linked to workplace anxiety. We also found a mediating effect of workplace anxiety on the relationship between proactivity and work-family conflict and observed that immediate supervisor perspective taking can weaken the positive relationship between employee proactivity and workplace anxiety. Moreover, immediate supervisor perspective taking buffers the indirect effects of employee proactivity on employee work-family conflict such that the relationship is weaker (versus stronger) among employees whose supervisors demonstrate lower (versus higher) perspective taking. Our results also indicate that EI reduces the positive associations between proactive behavior and workplace anxiety. EI weakens the indirect effects of proactive behavior on workfamily conflict such that the relationship is weaker (versus stronger) among employees with higher (versus lower) EI. Our findings contribute to the theory and research on proactivity and the work-family interface in three ways.

Firstly, our research shows that proactive behavior is positively associated with work-family conflict. To our knowledge, behavior-based conflict in the work-family conflict model by Greenhaus and Beutell (1985) has been relatively little examined in recent studies (Dierdorff and Ellington, 2008). Our results provide empirical support for the finding that proactive behavior spills over to the home domain and leads to work-family conflict. This result is consistent with those of previous studies and confirms the positive relationship between proactive behavior and work-family conflict (Bolino and Turnley, 2005; 


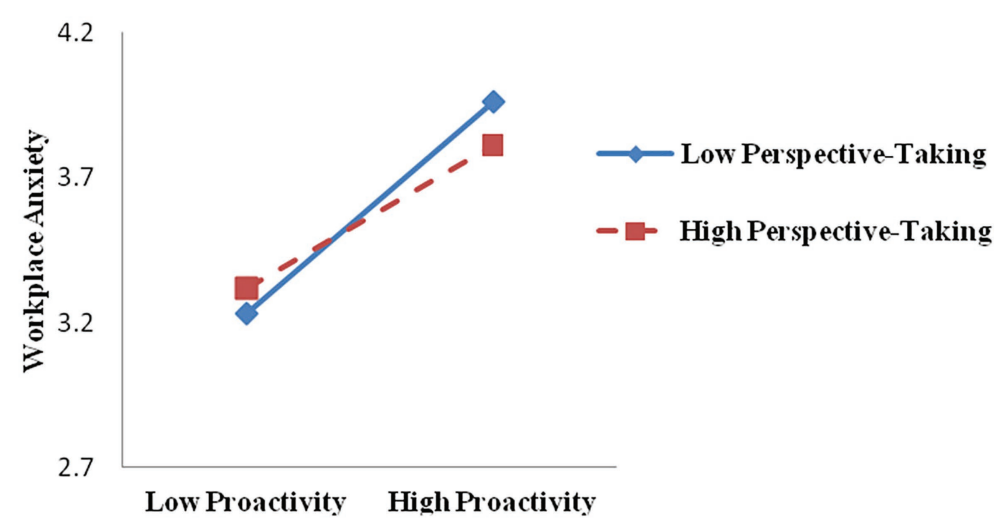

FIGURE 2 | Moderating effect of immediate supervisor perspective taking on the relationship between proactive behavior and workplace anxiety.

TABLE 4 | Conditional indirect effects.

\begin{tabular}{lllllc}
\hline Moderator & Level & Effect & Boot SE & Boot $\boldsymbol{p}$ & Cl \\
\hline Immediate & Low $(-1 \mathrm{SD})$ & 0.229 & 0.354 & 0.000 & $0.165-0.305$ \\
supervisor & High $(+1 \mathrm{SD})$ & 0.116 & 0.280 & 0.000 & $0.116-0.226$ \\
perspective taking & & & & &
\end{tabular}

$n=450$. Bootstrapping repetitions, $N=5,000$. Cl, confidence interval.

Harrison and Wagner, 2016; Zito et al., 2019). Furthermore, most previous studies have focused on the benefit of proactive behavior in organizations. Our results contribute to proactivity research by revealing the "dark side" of proactive behavior on the work-family interface. Our findings also answer the calls from Liu et al. (2019) and deepen our understanding of the consequences of proactive behavior.

Secondly, taking the COR theory and the W-HR model as our primary theoretical lens, we demonstrate through our research results that workplace anxiety plays a mediating role in the relationship between proactive behavior and work-family conflict. Although past studies have examined the relationship between specific proactive behavior and work-family conflict, investigation of the underlying mechanism of the relationship between proactive behavior and the work-family interface has been neglected (Bolino and Turnley, 2005; Harrison and Wagner, 2016; Zito et al., 2019). By examining the mediating effect of workplace anxiety, we provide empirical support for the idea that proactive behavior generates workplace anxiety, which in turn leads to work-family conflict. Hence, proactive behavior requiring resource consumption can lead to job strain and anxiety, which is more likely to spill over to the home domain and cause work-family conflict. Our results also extend and are consistent with the findings of Lin and Johnson (2015) and Pingel et al. (2019) that proactive behavior leads to resource loss, which results in anxiety and, ultimately, work-family conflict. Moreover, we found that proactive behavior is positively related to workplace anxiety; hence, behaving proactively has detrimental effects for employees. This result extends and highlights the findings by Cangiano et al. (2019) that proactive behavior was positively linked with workplace anxiety.
Thirdly, our results show that immediate supervisor perspective taking and employee EI moderate the indirect effects of proactive behavior on work-family conflict through workplace anxiety. While recent studies have argued that perspective taking can help leaders communicate and motivate subordinates more effectively (Galinsky and Schweitzer, 2016), few studies have empirically tested the role of leaders' perspective taking in an organizational context. In line with the COR theory and the W-HR model, our study supports the idea that subordinates working under leaders with high levels of perspective taking can acquire more work resources, which in turn prevents resource loss from the work domain to the family domain. Moreover, our results show that employees' EI can weaken the relationship between proactive behavior and work-family conflict. This result provides evidence that employees with high EI can regulate their emotions and consider the feelings of others at work, which in turn reduces their workplace anxiety caused by interpersonal tension from their proactive behavior. This finding is consistent with and extends the previous research of Amernic and Craig (2010). EI makes proactive employees pay more attention to social and relational contexts and consider their own self-regulation. Thus, employees who are proactive and have high EI seem to be "wiser," which thus weakens the negative effects of proactive behavior. Meanwhile, our results confirm that EI can be considered a key resource in protecting against resource loss stemming from proactive behavior (Halbesleben et al., 2014).

\section{CONCLUSION}

This study demonstrates that proactive behavior is positively related to work-family conflict and that workplace anxiety partially mediates this relationship. In addition, the study shows that immediate supervisor perspective taking and employee EI moderate the indirect effects of proactive behavior on work-family conflict through workplace anxiety. We provide empirical support for the idea that proactive behavior generates workplace anxiety, which in turn leads to work-family conflict. We hope that this study will spark interest among scholars 


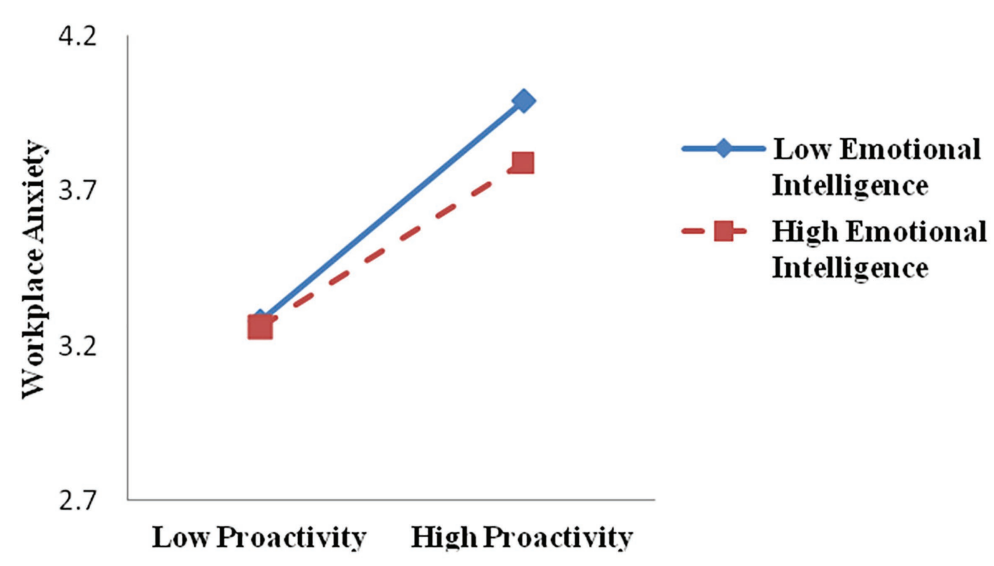

FIGURE 3 | Moderating effect of employee emotional intelligence on the relationship between proactive behavior and workplace anxiety.

TABLE 5 | Conditional indirect effects.

\begin{tabular}{lllllc}
\hline Moderator & Level & Effect & Boot SE & Boot $\boldsymbol{p}$ & Cl \\
\hline Emotional & Low $(-1 \mathrm{SD})$ & 0.218 & 0.336 & 0.000 & $0.157-0.228$ \\
intelligence & High $(+1 \mathrm{SD})$ & 0.116 & 0.270 & 0.000 & $0.114-0.222$ \\
\hline
\end{tabular}

$n=450$. Bootstrapping repetitions, $N=5,000, C l$, confidence interval

in the darker side of proactive behavior. We also hope that practitioners will pay attention to the negative effects of proactive behavior on employees' family lives while motivating them to take initiative.

\section{PRACTICAL IMPLICATIONS}

Our findings highlight some significant managerial implications for organizations. Firstly, our results suggest that proactive behavior spills over to the home domain and proactively correlates with work-family conflict both directly and indirectly. Hence, it is vital for organizations to realize that employees' proactive behavior may have detrimental effects on their family lives. Managers need to consider the "dark side" of proactive behavior and formulate supportive family policies for proactive employees. Organizations can also provide work-family segmentation policies, such as flextime, which can lower the impact of work on the family. These practices can help employees alleviate work-family conflicts caused by proactive behaviors. Secondly, our results show that proactive behavior is resourceconsuming, which causes proactive individuals to experience workplace anxiety. Thus, organizations can formulate policies and provide resources for proactive employees; for example, organizational line managers should be encouraged to provide support such as flexible work options, job autonomy, and emotional support that conveys compassion and understanding to support proactive employees. Organizations can also create a more inclusive and compatible organizational culture to reduce workplace anxiety caused by proactivity. Thirdly, our study shows that immediate supervisor perspective taking is a boundary condition that benefits proactivity and related outcomes.
This finding suggests that line managers' perspective taking helps them to more easily and effectively communicate with and motivate proactive employees. Thus, organizations should select line managers who are highly agreeable and skilled at perspective taking and should provide training to supervisors to help them improve their perspective taking. Such training will promote understanding between line managers and proactive employees. This practice can also alleviate the anxiety that may be generated by proactive behavior. Lastly, given that EI moderated the relationship between proactive behavior and work-family conflict, organizations should pay more attention to the potential value of EI in human resource management practice. Specifically, organizations can make hiring decisions based on applicants' EI and provide training courses to help employees improve their emotion management skills.

\section{LIMITATIONS AND FUTURE RESEARCH}

Despite the findings and the contributions made to the field, this study had some limitations that should be addressed. Firstly, although we collected data with a multisource, time-lagged design, the potential threat of common method bias still cannot be excluded. Because work-family conflict may also affect workplace behavior, we encourage future research to use a longitudinal design to investigate the reciprocal relationship between proactive behavior and work-family conflict to clarify causal relationships. Secondly, our data were collected only from enterprises located in Northeast China. There is some question as to whether our findings can be replicated in other countries. Therefore, to improve the generalizability of the present findings, we encourage future research to use samples from Western countries to test the generalizability of the findings. Thirdly, our research was based on a resource theoretical perspective and focused only on the impact of proactivity on work-family conflict to construct a moderated mediation model. Since other potential factors may affect employees' workplace anxiety and work-family conflict during the process, future research should identify other mechanisms between proactive behavior and work-family conflict. Finally, the work-family interface is generally 
considered culturally sensitive (Powell et al., 2009), and our research was conducted solely in the Chinese cultural context. Thus, a specific model that considers cultural characteristics (such as collectivism and power distance) as moderators might be more powerful in future studies.

\section{DATA AVAILABILITY STATEMENT}

The original contributions presented in the study are included in the article/supplementary material, further inquiries can be directed to the corresponding author.

\section{ETHICS STATEMENT}

The studies involving human participants were reviewed and approved by Ethics Committee of Jilin University of Finance

\section{REFERENCES}

Aiken, L. S., and West, S. G. (1991). Multiple Regression: Testing and Interpreting Interactions. Thousand Oaks, CA: Sage.

Altura, T. G., Rao, A. N., and Virick, M. (2020). Proactive personality as a double-edged sword: the mediating role of work-family conflict on employee outcomes. J. Career Dev. doi: 10.1177/0894845319899984

Amernic, J. H., and Craig, R. J. (2010). Accounting as a facilitator of extreme narcissism. J. Bus. Ethics 96, 79-93. doi: 10.1007/s10551-010-0450-0

Arlie, H. R. (1997). The Time Bind: When Work Becomes Home and Home Becomes Work. New York, NY: Macmillan.

Bateman, T. S., and Crant, J. M. (1993). The proactive component of organizational behavior: a measure and correlates. J. Organ. Behav. 14, 103-118. doi: 10.1002/ job.4030140202

Bernerth, J. B., and Aguinis, H. (2016). A critical review and best-practice recommendations for control variable usage. Pers. Psychol. 69, 229-283. doi: 10.1111/peps. 12103

Bindl, U. K., Parker, S. K., Totterdell, P., and Hagger-Johnson, G. (2012). Fuel of the self-starter: how mood relates to proactive goal regulation. J. Appl. Psychol. 97, 134-150. doi: 10.1037/a0024368

Binyamin, G., and Brender-Ilan, Y. (2018). Leaders's language and employee proactivity: enhancing psychological meaningfulness and vitality. Eur. Manag. J. 36, 463-473. doi: 10.1016/j.emj.2017.09.004

Bolino, M. C., and Turnley, W. H. (2005). The personal costs of citizenship behavior: the relationship between individual initiative and role overload, job stress, and work-family conflict. J. Appl. Psychol. 90, 740-748. doi: 10.1037/0021-9010.90.4.740

Bolino, M., Valcea, S., and Harvey, J. (2010). Employee, manage thyself: the potentially negative implications of expecting employees to behave proactively. J. Occup. Organ. Psychol. 83, 325-345. doi: 10.1348/09631 7910x493134

Brislin, R. W. (1980). "Cross-cultural research methods," in Environment and Culture. eds. I. Altman, A. Rapoport and J. F. Wohlwill (Boston, MA: Springer US), 47-82.

Buchwald, P. (2010). Test anxiety and performance in the framework of the conservation of resources theory. Cogn. Brain Behav. 14, 283-293.

Byron, K. (2005). A meta-analytic review of work-family conflict and its antecedents. J. Vocat. Behav. 67, 169-198. doi: 10.1016/j.jvb.2004.08. 009

Cai, Z., Parker, S. K., Chen, Z., and Lam, W. (2019). How does the social context fuel the proactive fire? A multilevel review and theoretical synthesis. J. Organ. Behav. 40, 209-230. doi: 10.1002/job.2347

Campbell, D. J. (2000). The proactive employee: managing workplace initiative. Acad. Manag. Exec. 14, 52-66. doi: 10.5465/ame.2000.4468066 and Economics. The patients/participants provided their written informed consent to participate in this study.

\section{AUTHOR CONTRIBUTIONS}

ZC contributed to study conception theoretical foundation, model development, and research design. ZC and YL contributed to the literature research, analysis and interpretation of data, and drafting of manuscript. All authors contributed to the article and approved the submitted version.

\section{FUNDING}

This study was supported by the Ministry of Education Humanities and Social Sciences Foundation Project of China (13XJC630002).

Cangiano, F., Parker, S. K., and Ouyang, K. (2020). Too proactive to switch off: when taking charge drains resources and impairs detachment. J. Occup. Health Psychol. 26, 142-154. doi: 10.1037/ocp0000265

Cangiano, F., Parker, S. K., and Yeo, G. B. (2019). Does daily proactivity affect well-being? The moderating role of punitive supervision. J. Organ. Behav. 40, 59-72. doi: 10.1002/job.2321

Carlson, K. D., and Wu, J. (2012). The illusion of statistical control: control variable practice in management research. Organ. Res. Methods 15, 413-435. doi: $10.1177 / 1094428111428817$

Cheng, B. H., and McCarthy, J. M. (2018). Understanding the dark and bright sides of anxiety: a theory of workplace anxiety. J. Appl. Psychol. 103, 537-560. doi: $10.1037 /$ apl0000266

Crant, J. M. (2000). Proactive behavior in organizations. J. Manag. 26, 435-462. doi: $10.1177 / 014920630002600303$

Daus, C. S., and Ashkanasy, N. M. (2005). The case for the ability-based model of emotional intelligence in organizational behavior. J. Organ. Behav. 26, 453-466. doi: 10.1002/job.321

De Dreu, C. K. W., Weingart, L. R., and Kwon, S. (2000). Influence of social motives on integrative negotiation: a meta-analytic review and test of two theories. J. Pers. Soc. Psychol. 78, 889-905. doi: 10.1037/00223514.78.5.889

Dewaele, J. M., Petrides, K. V., and Furnham, A. (2008). Effects of trait emotional intelligence and sociobiographical variables on communicative anxiety and foreign language anxiety among adult multilinguals: a review and empirical investigation. Lang. Learn. 58, 911-960. doi: 10.1111/j.14679922.2008.00482.x

Dierdorff, E. C., and Ellington, J. K. (2008). It's the nature of the work: examining behavior-based sources of work-family conflict across occupations. J. Appl. Psychol. 93, 883-892. doi: 10.1037/0021-9010.93.4.883

Doby, V. J., and Caplan, R. D. (1995). Organizational stress as threat to reputation: effects on anxiety at work and at home. Acad. Manag. J. 38, 1105-1123. doi: $10.5465 / 256622$

Edwards, M. R. (2006). The role of husbands' supportive communication practices in the lives of employed mothers. Marriage Fam. Rev. 40, 23-46. doi: 10.1300/ J002v40n04_03

Edwards, J. R., and Lambert, L. S. (2007). Methods for integrating moderation and mediation: a general analytical framework using moderated path analysis. Psychol. Methods 12, 1-22. doi: 10.1037/1082-989x.12.1.1

Falk, D. R., and Johnson, D. W. (1977). The effects of perspective-taking and egocentrism on problem solving in heterogeneous and homogeneous groups. J. Soc. Psychol. 102, 63-72. doi: 10.1080/00224545.1977.9713241

Fay, D., and Frese, M. (2001). The concept of personal initiative: an overview of validity studies. Hum. Perform. 14, 97-124. doi: 10.1207/s15327043 hup1401_06 
Fay, D., and Huttges, A. (2017). Drawbacks of proactivity: effects of daily proactivity on daily salivary cortisol and subjective well-being. J. Occup. Health Psychol. 22, 429-442. doi: 10.1037/ocp0000042

Flinchbaugh, C., Li, P., Luth, M. T., and Chadwick, C. (2016). Team-level high involvement work practices: investigating the role of knowledge sharing and perspective taking. Hum. Resour. Manag. J. 26, 134-150. doi: 10.1111/17488583.12098

Foster, B., Lomas, J., Downey, L., and Stough, C. (2018). Does emotional intelligence mediate the relation between mindfulness and anxiety and depression in adolescents? Front. Psychol. 9:2463. doi: 10.3389/fpsyg. 2018.02463

Frese, M., Garst, H., and Fay, D. (2007). Making things happen: reciprocal relationships between work characteristics and personal initiative in a fourwave longitudinal structural equation model. J. Appl. Psychol. 92, 1084-1102. doi: $10.1037 / 0021-9010.92 .4 .1084$

Fu, W., Wilhelm, L. O., Wei, Y., Zhou, G., and Schwarzer, R. (2020). Emotional intelligence and dyadic satisfaction buffer the negative effect of stress on prenatal anxiety and depressive symptoms in Chinese women who are pregnant with twins. Anxiety Stress Coping 33, 466-478. doi: 10.1080/ 10615806.2020.1745193

Fuller, B., and Marler, L. E. (2009). Change driven by nature: a meta-analytic review of the proactive personality literature. J. Vocat. Behav. 75, 329-345. doi: $10.1016 /$ j.jvb.2009.05.008

Fulmer, I. S., and Barry, B. (2004). The smart negotiator: cognitive ability and emotional intelligence in negotiation. Int. J. Confl. Manag. 15, 245-272. doi: 10.1108/eb022914

Galinsky, A. D., Ku, G., and Wang, C. S. (2005). Perspective-taking and selfother overlap: fostering social bonds and facilitating social coordination. Group Process. Intergr. Relat. 8, 109-124. doi: 10.1177/1368430205051060

Galinsky, A. D., and Moskowitz, G. B. (2000). Perspective-taking: decreasing stereotype expression, stereotype accessibility, and in-group favoritism. J. Pers. Soc. Psychol. 78, 708-724. doi: 10.1037/0022-3514.78.4.708

Galinsky, A. D., and Schweitzer, M. E. (2016). Why every great leader needs to be a great perspective taker. Lead. Lead. 2016, 32-37. doi: 10.1002/ lt1.20229

Gao, Y., Shi, J., Niu, Q., and Wang, L. (2013). Work-family conflict and job satisfaction: emotional intelligence as a moderator. Stress. Health 29, 222-228. doi: $10.1002 / \mathrm{smi} .2451$

George, J. M. (2000). Emotions and leadership: the role of emotional intelligence. Hum. Relat. 53, 1027-1055. doi: 10.1177/0018726700538001

Goldberg, L. S., and Grandey, A. A. (2007). Display rules versus display autonomy: emotion regulation, emotional exhaustion, and task performance in a call center simulation. J. Occup. Health Psychol. 12, 301-318. doi: 10.1037/ 1076-8998.12.3.301

Görgens-Ekermans, G., and Brand, T. (2012). Emotional intelligence as a moderator in the stress-burnout relationship: a questionnaire study on nurses. J. Clin. Nurs. 21, 2275-2285. doi: 10.1111/j.1365-2702.2012.04171.x

Grandey, A. A. (2003). When "the show must go on": surface acting and deep acting as determinants of emotional exhaustion and peer-rated service delivery. Acad. Manag. J. 46, 86-96. doi: 10.2307/30040678

Grant, A. M. (2013). Rocking the boat but keeping it steady: the role of emotion regulation in employee voice. Acad. Manag. J. 56, 1703-1723. doi: 10.5465/amj.2011.0035

Grant, A. M., and Ashford, S. J. (2008). The dynamics of proactivity at work. Res. Organ. Behav. 28, 3-34. doi: 10.1016/j.riob.2008.04.002

Grant, A. M., and Berry, J. W. (2011). The necessity of others is the mother of invention: intrinsic and prosocial motivations, perspective taking, and creativity. Acad. Manag. J. 54, 73-96. doi: 10.5465/amj.2011.59215085

Grant, A. M., Parker, S., and Collins, C. (2010). Getting credit for proactive behavior: supervisor reactions depend on what you value and how you feel. Pers. Psychol. 62, 31-55. doi: 10.1111/j.1744-6570.2008.01128.x

Greenhaus, J. H., and Beutell, N. J. (1985). Sources of conflict between work and family roles. Acad. Manag. Rev. 10, 76-88. doi: 10.5465/amr.1985.4277352

Gregory, B. T., Moates, K. N., and Gregory, S. T. (2011). An exploration of perspective taking as an antecedent of transformational leadership behavior. Leadersh. Org. Dev. J. 32, 807-816. doi: 10.1108/01437731111183748

Griffin, M. A., Neal, A., and Parker, S. K. (2007). A new model of work role performance: positive behavior in uncertain and interdependent contexts. Acad. Manag. J. 50, 327-347. doi: 10.5465/amj.2007.24634438
Grupe, D. W., and Nitschke, J. B. (2013). Uncertainty and anticipation in anxiety: an integrated neurobiological and psychological perspective. Nat. Rev. Neurosci. 14, 488-501. doi: 10.1038/nrn3524

Hahn, V. C., Frese, M., Binnewies, C., and Schmitt, A. (2012). Happy and proactive? The role of hedonic and eudaimonic well-being in business owners' personal initiative. Entrep. Theory Pract. 36, 97-114. doi: 10.1111/j.15406520.2011.00490.x

Halbesleben, J. R. B., Neveu, J. P., Paustian-Underdahl, S. C., and Westman, M. (2014). Getting to the "COR": understanding the role of resources in conservation of resources theory. J. Manag. 40, 1334-1364. doi: 10.1177/0149 206314527130

Harrison, S. H., and Wagner, D. T. (2016). Spilling outside the box: the effects of individuals' creative behaviors at work on time spent with their spouses at home. Acad. Manag. J. 59, 841-859. doi: 10.5465/amj.2013.0560

Hayes, A. F. (2013). Introduction to Mediation, Moderation, and Conditional Process Analysis: A Regression-Based Approach. New York, NY: Guilford Press.

Hobfoll, S. E. (1989). Conservation of resources: a new attempt at conceptualizing stress. Am. Psychol. 44, 513-524. doi: 10.1037//0003-066x.44.3.513

Huerta, M., Goodson, P., Beigi, M., and Chlup, D. (2017). Graduate students as academic writers: writing anxiety, self-efficacy and emotional intelligence. High. Educ. Res. Dev. 36, 716-729. doi: 10.1080/07294360.2016.1238881

Humphrey, R. H., Pollack, J. M., and Hawver, T. (2008). Leading with emotional labor. J. Manag. Psychol. 23, 151-168. doi: 10.1108/02683940810850790

Huo, Y., Chen, Z., and Lam, W. (2013). Proactivity is not enough: the role of perspective taking in enhancing the beneficial outcomes. Acad. Manag. Annu. Meet. Proc. 2013:12228. doi: 10.5465/ambpp.2013.12228abstract

Huo, Y., Chen, Z., Lam, W., and Woods, S. A. (2019). Standing in my customer's shoes: effects of customer-oriented perspective taking on proactive service performance. J. Occup. Organ. Psychol. 92, 255-280. doi: 10.1111/ joop. 12247

Jordan, P. J., Ashkanasy, N. M., Härtel, C. E. J., and Hooper, G. S. (2002). Workgroup emotional intelligence: scale development and relationship to team process effectiveness and goal focus. Hum. Resour. Manag. Rev. 12, 195-214. doi: 10.1016/S1053-4822(02)00046-3

Kahn, R. L., Wolfe, D. M., Quinn, R. P., Snoek, J. D., and Rosenthal, R. A. (1964). Organizational Stress: Studies in Role Conflict and Ambiguity. Oxford, England: John Wiley.

Kouchaki, M., and Desai, S. D. (2015). Anxious, threatened, and also unethical: how anxiety makes individuals feel threatened and commit unethical acts. J. Appl. Psychol. 100, 360-375. doi: 10.1037/a0037796

Ku, G., Wang, C. S., and Galinsky, A. D. (2015). The promise and perversity of perspective-taking in organizations. Res. Organ. Behav. 35, 79-102. doi: 10.1016/j.riob.2015.07.003

Lebel, R. D. (2017). Moving beyond fight and flight: a contingent model of how the emotional regulation of anger and fear sparks proactivity. Acad. Manag. Rev. 42, 190-206. doi: 10.5465/amr.2014.0368

Li, L. (2018). China's manufacturing locus in 2025: with a comparison of "made-in-China 2025" and "industry 4.0". Technol. Forecast. Soc. Chang. 135, 66-74. doi: 10.1016/j.techfore.2017.05.028

Lin, S. H., and Johnson, R. E. (2015). A suggestion to improve a day keeps your depletion away: examining promotive and prohibitive voice behaviors within a regulatory focus and ego depletion framework. J. Appl. Psychol. 100, 1381-1397. doi: 10.1037/apl0000018

Lin, W., and Yu, K. (2019). The enriching and depleting effects of workplace proactivity on work-family conflict. Acad. Manag. 2019:16689. doi: 10.5465/ AMBPP.2019.16689abstract

Liu, W., Tangirala, S., Lee, C., and Parker, S. K. (2019). New directions for exploring the consequences of proactive behaviors: introduction to the special issue. J. Organ. Behav. 40, 1-4. doi: 10.1002/job.2334

MacIntyre, P. D., and Gardner, R. C. (1994). The subtle effects of language anxiety on cognitive processing in the second language. Lang. Learn. 44 283-305. doi: 10.1111/j.1467-1770.1994.tb01103.x

MacLeod, C., and Mathews, A. (2012). Cognitive bias modification approaches to anxiety. Annu. Rev. Clin. Psychol. 8, 189-217. doi: 10.1146/annurevclinpsy-032511-143052

Mannor, M. J., Wowak, A. J., Bartkus, V. O., and Gomez-Mejia, L. R. (2016). Heavy lies the crown? How job anxiety affects top executive decision making in gain and loss contexts. Strateg. Manag. J. 37, 1968-1989. doi: 10.1002/ smj. 2425 
Martínez-Monteagudo, M. C., Inglés, C. J., Granados, L., Aparisi, D., and García-Fernández, J. M. (2019). Trait emotional intelligence profiles, burnout, anxiety, depression, and stress in secondary education teachers. Personal. Individ. Differ. 142, 53-61. doi: 10.1016/j.paid.2019.01.036

Matthews, L. S., Conger, R. D., and Wickrama, K. A. S. (1996). Work-family conflict and marital quality: mediating processes. Soc. Psychol. Q. 59, 62-79. doi: $10.2307 / 2787119$

Mayer, J. D., Caruso, D. R., and Salovey, P. (1999). Emotional intelligence meets traditional standards for an intelligence. Intelligence 27, 267-298. doi: 10.1016/S0160-2896(99)00016-1

McCarthy, J. M., Trougakos, J. P., and Cheng, B. H. (2016). Are anxious workers less productive workers? It depends on the quality of social exchange. $J$. Appl. Psychol. 101, 279-291. doi: 10.1037/apl0000044

Miceli, M., and Castelfranchi, C. (2005). Anxiety as an "epistemic" emotion: an uncertainty theory of anxiety. Anxiety Stress Coping 18, 291-319. doi: $10.1080 / 10615800500209324$

Michel, J. S., Kotrba, L. M., Mitchelson, J. K., Clark, M. A., and Baltes, B. B. (2011). Antecedents of work-family conflict: a meta-analytic review. J. Organ. Behav. 32, 689-725. doi: 10.1002/job.695

Moates, K. N., Harris, S. G., Field, H. S., and Armenakis, A. A. (2007). Perspective taking and leader-member exchange in supervisor/subordinate dyads: a hierarchical linear modeling investigation. Acad. Manag. 2007, 1-6. doi: 10.5465/ambpp.2007.26527926

Muller, D., Judd, C. M., and Yzerbyt, V. Y. (2005). When moderation is mediated and mediation is moderated. J. Pers. Soc. Psychol. 89, 852-863. doi: 10.1037/0022-3514.89.6.852

Netemeyer, R. G., Boles, J. S., and McMurrian, R. (1996). Development and validation of work-family conflict and family-work conflict scales. J. Appl. Psychol. 81, 400-410. doi: 10.1037/0021-9010.81.4.400

Parker, S. K., Atkins, P. W. B., and Axtell, C. M. (2008). "Building better workplaces through individual perspective taking: a fresh look at a fundamental human process," in International Review of Industrial and Organizational Psychology. eds. G. P. Hodgkinson and J. K. Ford (England: John Wiley \& Sons), 149-163.

Parker, S. K., Bindl, U. K., and Strauss, K. (2010). Making things happen: a model of proactive motivation. J. Manag. 36, 827-856. doi: 10.1177/ 0149206310363732

Parker, S. K., Wang, Y., and Liao, J. (2019). When is proactivity wise? A review of factors that influence the individual outcomes of proactive behavior. Annu. Rev. Organ. Psych. Organ. Behav. 6, 221-248. doi: 10.1146/annurevorgpsych-012218-015302

Parker, S. K., Williams, H. M., and Turner, N. (2006). Modeling the antecedents of proactive behavior at work. J. Appl. Psychol. 91, 636-652. doi: 10.1037/00219010.91.3.636

Pingel, R., Fay, D., and Urbach, T. (2019). A resources perspective on when and how proactive work behaviour leads to employee withdrawal. J. Occup. Organ. Psychol. 92, 410-435. doi: 10.1111/joop.12254

Podsakoff, P. M., MacKenzie, S. B., Lee, J. Y., and Podsakoff, N. P. (2003). Common method biases in behavioral research: a critical review of the literature and recommended remedies. J. Appl. Psychol. 88, 879-903. doi: 10.1037/0021-9010.88.5.879

Powell, G. N., Francesco, A. M., and Ling, Y. (2009). Toward culture-sensitive theories of the work-family interface. J. Organ. Behav. 30, 597-616. doi: 10.1002/job.568

Preacher, K. J., Rucker, D. D., and Hayes, A. F. (2007). Addressing moderated mediation hypotheses: theory, methods, and prescriptions. Multivar. Behav. Res. 42, 185-227. doi: 10.1080/00273170701341316

Rasool, S. (2021). How toxic workplace environment effects the employee engagement: the mediating role of organizational support and employee wellbeing. Int. J. Environ. Res. Public Health 18:2294. doi: 10.3390/ ijerph 18052294

Rasool, S. F., Samma, M., Wang, M., Zhao, Y., and Zhang, Y. (2019). How human resource management practices translate into sustainable organizational performance: the mediating role of product, process and knowledge innovation. Psychol. Res. Behav. Manag. 12, 1009-1025. doi: 10.2147/PRBM.S204662

Rasool, S. F., Wang, M., Zhang, Y., and Samma, M. (2020). Sustainable work performance: the roles of workplace violence and occupational stress. Int. J. Environ. Res. Public Health 17:912. doi: 10.3390/ijerph17030912
Rodell, J. B., and Judge, T. A. (2009). Can "good" stressors spark "bad" behaviors? The mediating role of emotions in links of challenge and hindrance stressors with citizenship and counterproductive behaviors. J. Appl. Psychol. 94, 1438-1451. doi: 10.1037/a0016752

Ryan, R. M., and Deci, E. L. (2008). "Self-determination theory and the role of basic psychological needs in personality and the organization of behavior," in Handbook of Personality: Theory and Research. eds. L. A. Pervin, O. John and R. W. Robins (New York, NY, US: The Guilford Press), 654-678.

Salovey, P., and Rosenhan, D. L. (1989). "Mood states and prosocial behavior," in Handbook of Psychology. eds. H. Wagner and A. Manstead (New York, NY: Wiley and Sons), 371-391.

Samma, M., Zhao, Y., Rasool, S. F., Han, X., and Ali, S. (2020). Exploring the relationship between innovative work behavior, job anxiety, workplace ostracism, and workplace incivility: empirical evidence from small and medium sized enterprises (SMEs). Healthcare 8:508. doi: 10.3390/healthcare 8040508

Sánchez-Álvarez, N., Extremera, N., and Fernández-Berrocal, P. (2016). The relation between emotional intelligence and subjective well-being: a metaanalytic investigation. J. Posit. Psychol. 11, 276-285. doi: 10.1080/17439760. 2015.1058968

Sarason, I. G., Pierce, G. R., and Sarason, B. R. (eds.) (1996). "Domains of cognitive interference," in Cognitive Interference: Theories, Methods, and Findings (Hillsdale, NJ, US: Lawrence Erlbaum Associates, Inc.), 139-152.

Schneider, T. R., Lyons, J. B., and Khazon, S. (2013). Emotional intelligence and resilience. Personal. Individ. Differ. 55, 909-914. doi: 10.1016/j. paid.2013.07.460

Schutte, N. S., Malouff, J. M., Simunek, M., McKenley, J., and Hollander, S. (2002). Characteristic emotional intelligence and emotional well-being. J. Cogn. Emot. 16, 769-785. doi: 10.1080/02699930143000482

Sell, M., and Schuler, R. (1981). Role conflict and role ambiguity: integration of the literature and directions for future research. Hum. Relat. 34, 43-71. doi: 10.1177/001872678103400104

Shih, M., Wang, E., Trahan Bucher, A., and Stotzer, R. (2009). Perspective taking: reducing prejudice towards general outgroups and specific individuals. Group Process. Intergr. Relat. 12, 565-577. doi: 10.1177/1368430209337463

Spreitzer, G. M. (1995). Psychological empowerment in the workplace: dimensions, measurement, and validation. Acad. Manag. 38, 1442-1465. doi: 10.5465/256865

Spychala, A., and Sonnentag, S. (2011). The dark and the bright sides of proactive work behaviour and situational constraints: longitudinal relationships with task conflicts. Eur. J. Work Organ. Psychol. 20, 654-680. doi: 10.1080/ 1359432x.2010.487646

Story, L. B., and Repetti, R. (2006). Daily occupational stressors and marital behavior. J. Fam. Psychol. 20, 690-700. doi: 10.1037/0893-3200.20.4.690

Strauss, K., Parker, S. K., and O'Shea, D. (2017). When does proactivity have a cost? Motivation at work moderates the effects of proactive work behavior on employee job strain. J. Vocat. Behav. 100, 15-26. doi: 10.1016/j.jvb.2017.02.001

Summerfeldt, L. J., Kloosterman, P. H., Antony, M. M., and Parker, J. D. A. (2006). Social anxiety, emotional intelligence, and interpersonal adjustment. J. Psychopathol. Behav. Assess. 28, 57-68. doi: 10.1007/s10862-006-4542-1

Sun, J., Li, W. D., Li, Y., Liden, R. C., Li, S., and Zhang, X. (2020). Unintended consequences of being proactive? Linking proactive personality to coworker envy, helping, and undermining, and the moderating role of prosocial motivation. J. Appl. Psychol. 106, 250-267. doi: 10.1037/apl0000494

ten Brummelhuis, L. L., and Bakker, A. B. (2012). A resource perspective on the work-home interface: the work-home resources model. Am. Psychol. 67, 545-556. doi: 10.1037/a0027974

Thatcher, J. B., Loughry, M. L., Lim, J., and McKnight, D. H. (2007). Internet anxiety: an empirical study of the effects of personality, beliefs, and social support. Inf. Manag. 44, 353-363. doi: 10.1016/j.im.2006.11.007

Thomas, J. P., Whitman, D. S., and Viswesvaran, C. (2010). Employee proactivity in organizations: a comparative meta-analysis of emergent proactive constructs. J. Occup. Organ. Psychol. 83, 275-300. doi: 10.1348/096317910X502359

Tornau, K., and Frese, M. (2015). Construct clean-up in proactivity research: a meta-analysis on the nomological net of work-related proactivity concepts and their incremental validities. Appl. Psychol. 64, 626-636. doi: 10.1111/ apps. 12045

Trougakos, J. P., Chawla, N., and McCarthy, J. M. (2020). Working in a pandemic: exploring the impact of COVID-19 health anxiety on work, family, and health outcomes. J. Appl. Psychol. 105, 1234-1245. doi: 10.1037/apl0000739 
Urbach, T., and Weigelt, O. (2019). Time pressure and proactive work behaviour: a week-level study on intraindividual fluctuations and reciprocal relationships. J. Occup. Organ. Psychol. 92, 931-952. doi: 10.1111/joop.12269

Van Rooy, D. L., and Viswesvaran, C. (2004). Emotional intelligence: a metaanalytic investigation of predictive validity and nomological net. J. Vocat. Behav. 65, 71-95. doi: 10.1016/S0001-8791(03)00076-9

Wong, C.-S., and Law, K. S. (2002). The effects of leader and follower emotional intelligence on performance and attitude: an exploratory study. Leadersh. Q. 13, 243-274. doi: 10.1016/S1048-9843(02)00099-1

Wu, C. H., and Parker, S. K. (2017). The role of leader support in facilitating proactive work behavior: a perspective from attachment theory. J. Manag. 43, 1025-1049. doi: 10.1177/0149206314544745

Zeidner, M., Matthews, G., and Roberts, R. D. (2012). The emotional intelligence, health, and well-being nexus: what have we learned and what have we missed? Appl. Psychol. Health Well-Being 4, 1-30. doi: 10.1111/j.1758-0854.2011.01062.x

Zhang, M. J., Law, K. S., and Wang, L. (2020). The risks and benefits of initiating change at work: social consequences for proactive employees who take charge. Pers. Psychol. doi: 10.1111/peps.12423
Zhou, X., Rasool, S. F., and Ma, D. (2020). The relationship between workplace violence and innovative work behavior: the mediating roles of employee wellbeing. Healthcare 8:332. doi: 10.3390/healthcare8030332

Zito, M., Colombo, L., Borgogni, L., Callea, A., Cenciotti, R., Ingusci, E., et al. (2019). The nature of job crafting: positive and negative relations with job satisfaction and work-family conflict. Int. J. Environ. Res. 16:1176. doi: 10.3390/ ijerph 16071176

Conflict of Interest: The authors declare that the research was conducted in the absence of any commercial or financial relationships that could be construed as a potential conflict of interest.

Copyright (C) 2021 Cui and Li. This is an open-access article distributed under the terms of the Creative Commons Attribution License (CC BY). The use, distribution or reproduction in other forums is permitted, provided the original author(s) and the copyright owner(s) are credited and that the original publication in this journal is cited, in accordance with accepted academic practice. No use, distribution or reproduction is permitted which does not comply with these terms. 